\title{
La foto-elicitación en la formación permanente de maestros de educación primaria
}

\section{Photo-elicitation in lifelong learning of teachers of elementary education}

Dr. Antonio Bautista García-Vera es Docente de la Universidad Complutense de Madrid (España) (bautista@edu.ucm.es) (http://orcid.org/0000-0002-5194-7419)

Recibido: 2016-12-12 / Revisado: 2017-03-29 / Aceptado: 2017-04-06 / Publicado: 2017-07-01

\section{Resumen}

Este artículo versa sobre un plan de formación permanente del profesorado promovido y apoyado en las fotografías realizadas por dos maestras en sus aulas para, posteriormente, en dos grupos de discusión, uno para cada clase, reflexionar y debatir sobre el contenido de las mismas (foto-elicitación). Los fundamentos de dicho plan se asientan en tres ámbitos de teorización: la reflexión del profesorado sobre la propia práctica, la unión de la imagen experiencial con la toma de fotos por los docentes $y$, finalmente, el valor de la foto-elicitación como medio de narración. El interrogante generador de esta propuesta de desarrollo profesional de maestros fue ¿cómo poder materializar o representar en diferido la imagen experiencial docente sobre las vivencias en su aula? Como respuesta, se analiza si la foto-elicitación recrea fuera de la acción lo que ocurrió en ella, y hace visibles los conflictos y dilemas éticos presentes en el aula. Se concluye que estas sesiones fotográficas son válidas para analizar la toma de decisiones de ambas maestras, porque al preguntarles por ellas se les obliga a explicitar $y$, por lo tanto, a ser conscientes de sus teorías, creencias y valores. Se observa que el cambio en el profesorado solo es posible cuando este llega a ese nivel de conciencia y de lo que implica en su práctica docente.

Descriptores: Formación del profesorado, relación escuela-padres, indagación narrativa visual, fotoelicitación, investigación-acción.

\section{Abstract}

In this article we present and analyze a plan of teacher training. This plan is promoted and supported in the photographs taken by two teachers in their classrooms. Subsequently, through two focus groups, one for each class, we reflect and debate on the content of the photographs. This study is based on three areas of theorizing: teacher reflection on own practice, the essence of experiential image and multimodal literacy of teacher and, finally, the value of the photo- elicitation as a means of storytelling. The question generator that plan was how to materialize represent delayed or experiential image of the teacher to encourage description and, therefore, understand-

Forma sugerida de citar: Bautista García-Vera, A. (2017). La foto-elicitación en la formación permanente de maestros de educación primaria. Alteridad, 12(2), 202-214. https://doi.org/10.17163/alt.v12n1.2017.06. 
ing the experiences of your practice? The response we obtained using photo - elicitation is helping us to further investigate with rigor in human experiences unrelated to the hegemonic visual communication methodologies. Among its benefits within the teacher training, is to recreate the action out of what happened in it and, in parallel, offering the possibility of making visible and discuss conflicts and ethical dilemmas present in it. Thus, the photo- elicitation situations are warm to analyze how and why a teacher has made a decision

\section{Introducción 1}

El contenido de este artículo versa sobre el análisis y valoración de un plan de formación permanente del profesorado en dos aulas de Educación Primaria de los colegios públicos Jaime Vera y Concepción Arenal de Madrid (España). Este trabajo se ubica dentro del proyecto de investigación iniciado en 2012 y orientado a indagar la naturaleza de las relaciones entre las familias de ambos centros educativos, promovidas por narraciones biográfico-culturales, texto-visuales y grupales, iniciadas y apoyadas por cada profesora en su aula y continuadas por los padres en sus contextos familiar y social. Para este fin, se crearon reuniones de las maestras con esas familias dirigidas a crear historias con fotografías sobre sus respectivos países, barrios, familias, etcétera. En esas sesiones de narración y discusión ante una fotografía se han desencadenado interesantes procesos formativos que han favorecido el desarrollo personal y social de padres, madres y alumnos, así como la mejora profesional de ambas maestras.

Ubicados en ese contexto de investigación, en este artículo nos centramos de forma particular en el último aspecto señalado, que se inició en el mes de enero de 2015, y concretizado en la toma y proyección de fotografías por parte de las maestras para conocer la influencia de esas situaciones en su desarrollo profesional. De forma especial, se analiza el valor de esas imágenes para representar sus experiencias docentes en el aula y, posteriormente, comentarlas y discutirlas junto a and no other, because when asked by a choice made is forced to explain his theories, beliefs, values, attitudes.., and only when made explicit, when subjected to public scrutiny, is aware of them. We note that the change in teachers is only possible when it is aware of his theories, beliefs ... and what they entail in teaching.

Keywords: Teacher training, school-parent relationship, visual narrative inquiry, photo- elicitation, action-research.

dos miembros del equipo de investigación y con algunos alumnos y padres cuando era preciso. El tema de este texto es, por tanto, el desarrollo profesional de docentes orientado por la reflexión que hacen sobre aspectos concretos de sus prácticas en el aula y centro representados fotográficamente. Consideramos que la novedad de la investigación reside en incluir la foto-elicitación en la formación docente; es decir, en poner cámaras fotográficas en manos de maestros y maestras y, al analizar las imágenes capturadas, poder explicitar las teorías y creencias que dirimen los dilemas éticos emergentes en su práctica de enseñanza. Observaremos que dichas fotografías ayudan al profesorado a recordar sus pensamientos y emociones vividas en la acción.

\section{Antecedentes}

Los antecedentes que fundamentan este trabajo se ubican en tres ámbitos de estudio: la reflexión del profesorado sobre la propia práctica, el valor de la imagen experiencial de los docentes y, finalmente, la foto-elicitación como medio de narración.

\subsection{La reflexión del profesorado sobre la propia práctica}

Existe una extensa teorización sobre el valor de la reflexión de los profesionales sobre la propia práctica para mejorarla (Gimeno, 1989; McKerman, 2008; Schön, 1992). Se puede ayudar a los docentes a mejorar su trabajo cuando son conscien- 
tes de sus creencias teorías, actitudes, valores... y, para ello, se les "obliga" a explicitarlas. Esto sucede porque se les cuestiona y pregunta por lo que hacen. Elliot (1992) sistematizó estos procesos de reflexión sobre la práctica en bucles de Investigación-Acción. Cada uno está configurado por un procedimiento que consta de las tres fases siguientes:

1. Planificar la enseñanza o concretar en un documento cuáles son las finalidades, los contenidos de cultura, los materiales, etcétera, que las profesoras-tutoras (en nuestro caso) van a trabajar y necesitar durante un periodo de tiempo.

2. Desarrollar el plan y registrar momentos del mismo. Hay que realizar lo planificado y capturar información sobre lo sucedido en ese proceso. Ante la dificultad de reflexionar sobre la acción durante la acción, es necesario hacerlo después de haberla finalizado. Para evitar el olvido o pérdida de los detalles sobre lo que se considera relevante, es necesario grabarlos. ¿Qué herramientas de las familias tecnológicas, son necesarias para ayudar al profesorado a registrar la acción y reflexionar sobre ella? Consideramos que son aquellas que tienen como función primaria producir información (grabadoras). Nosotros propusimos que lo hiciesen principalmente ambas maestras, capturando fotográficamente esos instantes, es decir, nos situamos en el grupo de herramientas de la imagen fija. Evidentemente, para poder narrar con cámaras fotográficas fue necesario que tuvieran un conocimiento básico de este lenguaje visual.

3. Analizar, cuestionar, discutir, reflexionar sobre lo que allí ocurrió. Después de haber ejecutado el plan, hay que reflexionar sobre el valor de lo acontecido en su desarrollo; nosotros lo hemos hecho mediante situaciones de foto-elicitación. El resultado de esta fase ha llevado a un nuevo conocimiento sobre las decisiones tomadas, sobre las razones o porqués de las mismas $y$, consecuentemente, sobre las teorías, creencias, etcétera, que subyacen en ellas. Este conocimiento generado va enriqueciendo o mejorando poco a poco el plan de trabajo del siguiente bucle de Investigación-Acción y, consecuentemente, la formación de las profesoras participantes.

Para Lemon (2007), la reflexión del profesorado sobre la propia práctica se ha considerado como un medio para mejorar su trabajo, como una práctica moral, como una herramienta de emancipación y desarrollo de su autonomía profesional. Las diferentes consideraciones que se ha hecho de la práctica reflexiva por parte de docentes en las últimas décadas han sido recogidas por Zeichner (2010), habiendo cierta unanimidad en la teorización realizada de que la práctica reflexiva conlleva los procesos típicos de la InvestigaciónAcción para mejorar el trabajo docente.

\subsection{El valor de la imagen experiencial del profesorado}

La imagen experiencial en el contexto de la formación permanente de maestros es entendida como la representación mental que hacen los profesores de los acontecimientos vividos en su práctica docente en sus ámbitos de trabajo. Estas imágenes mentales, fruto de la experiencia, en alguna medida, soportan las teorías y creencias de maestros y maestras, y, por lo tanto, son valiosas para revivir los acontecimientos que representan cuando se piensa sobre ellos fuera del aula. En este sentido, consideramos que las imágenes fotográficas son un medio adecuado para materializar y, por lo tanto, para hacer visible las imágenes experienciales del profesorado y que, a su vez, están conformadas por sus creencias y teorías sobre educación.

De esta forma, en ámbitos de formación docente en los últimos tres decenios, la imagen experiencial pasó de ser una representación mental de elementos físicos a una manera de presentar 
experiencias sobre la enseñanza vividas en contextos educativos. Pero este cambio de significado no ha ido acompañado de procedimientos que ayuden al profesorado a concretar icónicamente las vivencias sobre su trabajo en colegios, posiblemente debido a la dificultad de materializar esta idea de imagen experiencial. En esta situación, queda sin responder la siguiente cuestión que justifica este proyecto ¿cómo materializar o representar en diferido la imagen experiencial de dos maestras para fomentar la concreción, análisis y, consiguiente comprensión, de las vivencias de su práctica en sus aulas y centros? La propuesta que indagamos para responder a esta cuestión es la de usar la cámara fotográfica y el lenguaje visual que soporta (Kellner, 2004).

\subsection{La foto-elicitación como medio de narración}

Según hemos indicado, la foto-elicitación es un procedimiento que permite a una persona recordar y evocar una situación vivida, un objeto, etcétera, mediante una fotografía que previamente ha hecho de ellos (Clark-Ibáñez, 2007; Harper, 2002). También, según hemos apuntado en el apartado precedente, puede ser un medio de reflexión y conocimiento de las propias teorías y creencias cuando se interroga a los maestros y maestras por lo que hacen, por las decisiones que toman, etcétera, en su práctica docente, a través de las imágenes que toman en el aula con una cámara fotográfica. Estos procesos van unidos a la indagación narrativa (Bruner, 2000; Clandinin y Connelly, 2000) y a la indagación narrativa visual (Bach, 2007; Lemon, 2007), que hacen referencia a la búsqueda en la propia experiencia para relatar y, por lo tanto, clarificar y conocer mejor los episodios propios vividos. En este concepto de indagación narrativa subyace la idea de que la experiencia puede ser considerada como una historia que, como tal, puede ser contada. Esta indagación es la que se realiza durante la fotoelicitación, cuando otros profesores del centro, investigadores que trabajan como observadores externos, o algunos padres y alumnos, interrogan a un maestro sobre alguna acción desarrollada o algún acontecimiento vivido en su aula que ha fotografiado y somete a análisis y discusión.

También, según Lemon (2007), la narrativa visual en el ámbito institucional de una escuela puede ser una herramienta icónica para las pantallas de las aulas y pasillos escolares, para promocionar a las escuelas mediante carteles en el acceso principal a ese centro. De igual forma, es un medio de relación entre las familias y escuelas en el periódico semanal. Pero sobre todo, algo que se olvida con facilidad, es que es una herramienta adecuada para la reflexión del profesorado sobre lo que ocurre en su aula.

Finalmente, hay que indicar que el valor de la foto-elicitación reside en el análisis y debate en grupo, porque esta situación reporta un contenido moral al proceso de formación docente, porque con las aportaciones de los participantes se va construyendo una corresponsabilidad del conocimiento construido y del valor ético de las decisiones tomadas que, en el futuro, orientan las tareas de enseñanza de los maestros implicados en el contexto de su aula y centro (Bautista, 2014).

\section{Objetivos}

Los objetivos propuestos para conocer cómo afectaba la discusión apoyada en situaciones de foto-elicitación al desarrollo profesional de las dos profesoras participantes fueron:

a. Analizar la relación entre las imágenes experienciales que tienen estas dos maestras sobre su práctica profesional en el aula y las imágenes fotográficas que realizan de los elementos o momentos de la misma que consideran importantes.

b. Conocer si las sesiones de foto-elicitación ayudan a ambas profesoras a cambiar su trabajo docente. 


\section{Método de investigación e intervención}

Por la naturaleza experiencial de los datos necesarios para responder a los objetivos de esta investigación, su diseño se basa en dos estudios de caso (Stake, 1989), correspondientes a dos maestras pertenecientes a los colegios públicos Jaime Vera y Concepción Arenal de Madrid. Este diseño metodológico permitirá replicar categorías y observar la vida de estas profesoras en su colegio en dos contextos distintos.

Los datos que permiten responder a los anteriores objetivos se obtienen mediante dos grupos de discusión (Barbour, 2013), vertebrados en torno a dos tipos de sesiones que denominamos: foto-elicitación y audio-reflexión.

Sesiones de foto-elicitación. Se celebran cada dos semanas. Durante ese tiempo, cada maestra toma fotografías de los sucesos, tareas, comportamientos, etcétera que considera más relevantes e interesantes de la vida en su aula y otros espacios del centro. Transcurrido cada periodo de 14 días y de forma independiente para cada docente, tiene lugar la mencionada reunión de unos 75 minutos, en sus respectivos horarios de exclusiva. Para ello, se proyectan las fotografías capturadas por cada una de las dos profesoras participantes, junto a dos miembros del grupo de investigación, otras maestras de sus colegios, y la representación de padres y alumnos, con la finalidad de comentar las motivaciones que llevaron a cada una tomar sus fotos. A continuación, el resto de contertulios formula cuestionamientos o dudas sobre el contenido de las imágenes y de las razones aportadas por las docentes y el alumnado (si es necesario), bien sobre la decisión tomada en un momento determinado del aula, bien sobre las tareas realizadas por los estudiantes, bien sobre el uso que están haciendo de los medios, etcétera.

Sesiones de audio-reflexión. Las sesiones de foto-elicitación se están grabando en audio con una doble intención investigadora. Una para poder analizar las manifestaciones de la maestra y responder a la cuestión planteada en el primer objetivo, relacionada con la naturaleza epistemológica de la representación fotográfica que hace la docente de las vivencias contenidas en su mente. En segundo lugar, para poder codificar y elaborar la información aportada en la sesión de fotoelicitación y poder abordar el segundo objetivo.

Según se adelantó en el resumen, el grupo de discusión que realiza esta reflexión está constituido por la maestra, los miembros del equipo de indagación que estuvieron presentes en la anterior sesión de foto-elicitación y algunos padres y estudiantes cuando el contenido de las fotografías lo requería por estar ellos implicados en las mismas.

Los padres dieron su conformidad para poder utilizar las fotografías donde aparecen sus hijos siempre que sea con fines docentes e investigadores.

\subsection{Categorías de análisis}

Para responder al primer objetivo de conocimiento, el grupo de investigación elaboró una "categoría previa" a utilizar en el análisis de datos que denominamos "nivel de correspondencia entre la imagen mental de cada maestra y el contenido de la fotografía". Para provocar esa información concreta, en las sesiones de foto-elicitación que componen y vertebran cada uno de los dos grupos de discusión, regularmente e independientemente del contenido de la preocupación o motivación por la que se había tomado esa imagen, se formulaban estas dos preguntas a cada una de las dos profesoras:

- ¿Qué tenías en tu mente cuando hiciste esa fotografía?

- ¿Posteriormente, te ha ayudado la visión de esa imagen para recordar lo que había en tu mente como consecuencia de lo vivido en aquellos momentos en el aula?

También, en el análisis, se está haciendo una codificación "basada en los datos" (Gibbs, 2012), que nos lleva a la construcción de las "categorías emergentes" de este estudio. 


\section{Resultados}

En este apartado presentamos una selección representativa de los datos recogidos entre enero de 2015 y junio de 2016. Con ellos pretendemos ilustrar la naturaleza de las categorías de conocimiento que respondan a los dos objetivos propuestos.

\subsection{Resultados vinculados a la catego- ría previa}

Como ya se ha comentado, en diferentes momentos, los miembros del grupo de discusión pertenecientes al equipo de investigación formulaban la pregunta sobre el nivel de ayuda que suponía a cada profesora la presencia de cada fotografía en las sesiones de foto-elicitación. A lo largo de estos meses, comprobamos que la tendencia de sus respuestas ha sido afirmativa; es decir, la imagen ha ayudado a las dos maestras a recordar y evocar dos tipos o niveles de información: conceptual y afectivo, según puede verse en estos datos:

"Miembro del Grupo 1 (M.G1): Siguiendo con esa pregunta repetitiva, que ya conocerás, y después de estas sesiones de análisis de situaciones de tu trabajo en el aula apoyado en fotografías que tú hiciste, ¿hasta qué punto te están ayudando?
Maestra 1 (M1): Pues mira, para mi sorpresa, al principio creía que me ayudarían a recordar acontecimientos, cosas sobre las tareas que hacíamos y no salían lo bien que yo pretendía, pero he descubierto que, en muchas ocasiones, y esto ya lo he dicho en otras reuniones, cuando la fotografía era sobre algún problema personal de algún alumno, o sobre la relación con algún padre o compañero que tenía un componente emocional, al ver la fotografía, no solo recordaba, sino también revivía esa emoción de disgusto o tristeza que había sentido en aquellos momentos" (Fragmento de la sesión del día 13/05/2015).

Otro de los días, la maestra 1 comentó:

"Maestra1 (M1): He pensado que estas fotografías me ayudan a recordar lo que viví en una situación ya pasada porque en el momento de hacerla, en cuestión de segundos, quiero recoger todo lo que me había impresionado y llamado la atención en ese instante. Por ejemplo, en la foto que comenté en la sesión anterior (ver foto número 1), cuando uno de los alumnos empezó a gritar para llamar la atención, era tal la confusión de aquellos momentos, donde todos los niños y yo misma estábamos bloqueados, que hice la foto recogiendo la expresión de los dos que se tapaban los oídos, así como la cara de desorientación de los otros, de no saber qué hacer" (Fragmento de la sesión del día 25/02/2015).

\section{Fotografía 1}

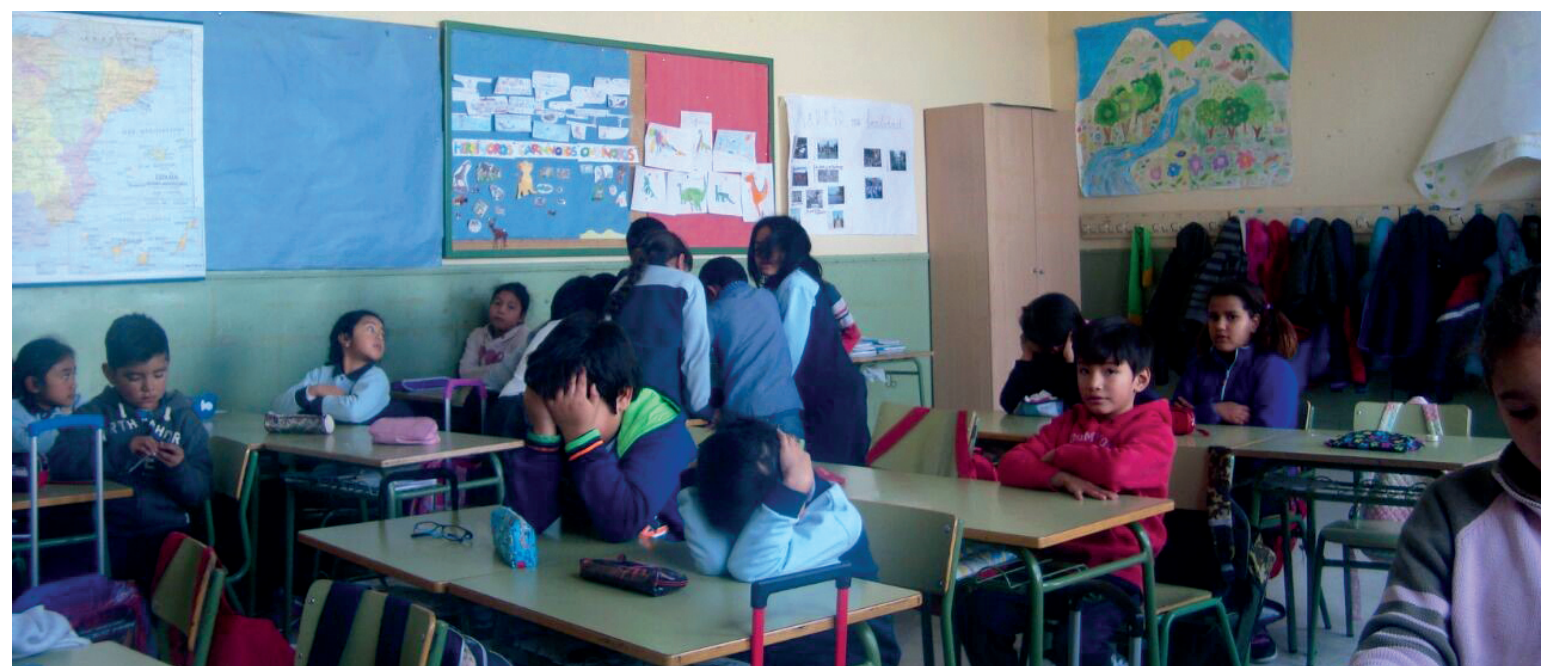


Ante una pregunta análoga formulada por el grupo de discusión del colegio número 2, en una de las sesiones la maestra 2 comentó:

"Maestra 2 (M2): Pues sí, voy comprobando que cuando hago una fotografía es por dos razones. Una, porque en ese instante ocurre algo que no entiendo de lo que está pasando o de lo que veo en clase. Un ejemplo de esto que digo fue cuando la niña de la foto de espalda que lleva dos años de retraso curricular (ver fotografía 2) está sentada en una silla que le viene pequeña. Con esa fotografía quise plasmar esa anomalía, ese contraste.

Fotografía 2.

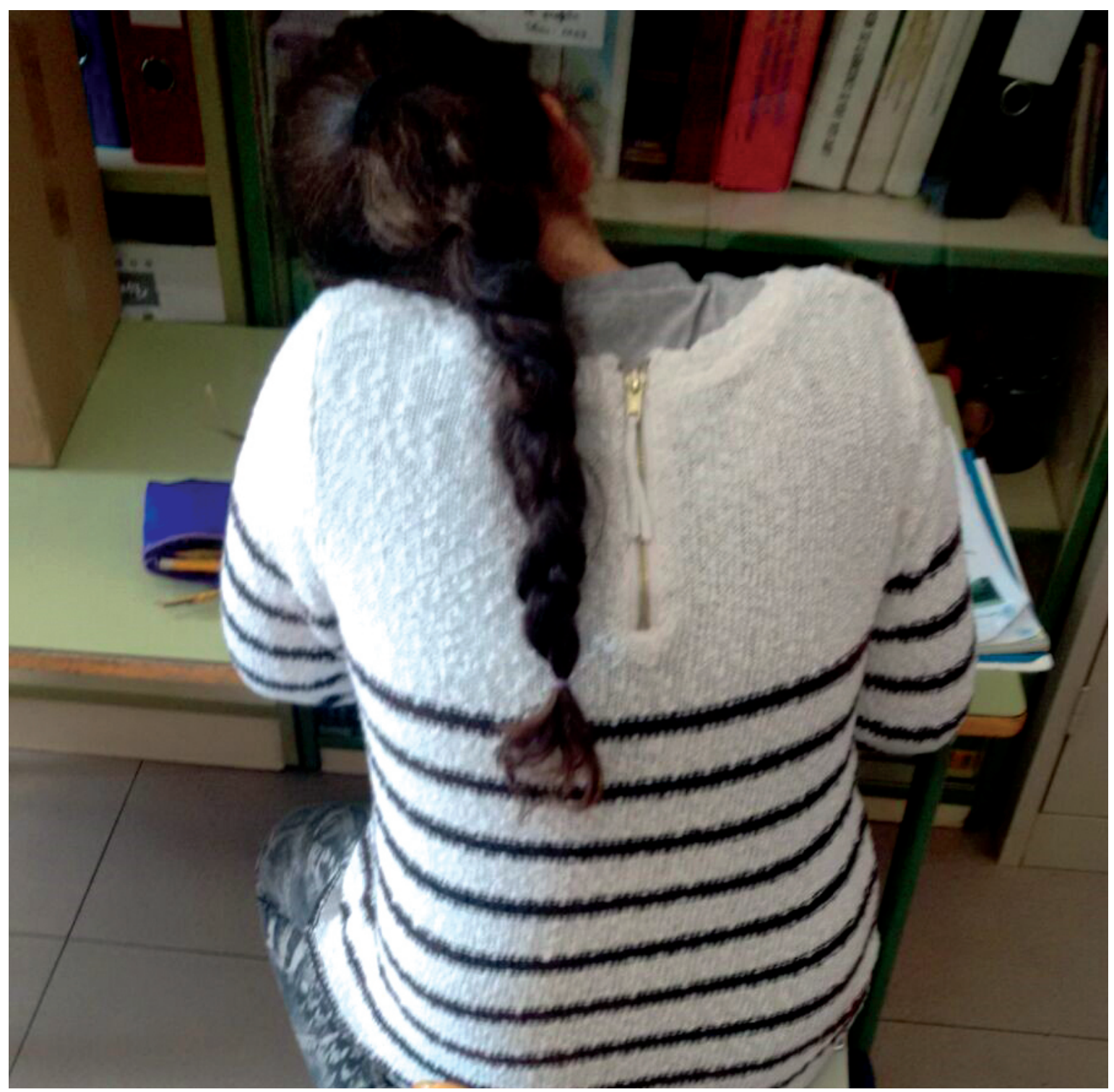

Miembro del grupo 2 (M.G.2): ¿Y la otra razón que has aludido por la que decides hacer una fotografía cuando estás en el colegio?
M2: Sí, la segunda razón, responde a las impresiones y emociones que noto en un momento. Por ejemplo, cuando estaba vigilando el recreo 
$\mathrm{Y}$ vi que $\mathrm{X}$ e $\mathrm{Y}$ (alumnos) se estaban dando patadas (ver fotografía 3), sentí esa violencia y la grabé encuadrando las piernas en diagonal, incli- nadas, cruzadas". (Fragmento de la sesión del día 11/02/2016).

\section{Fotografía 3.}

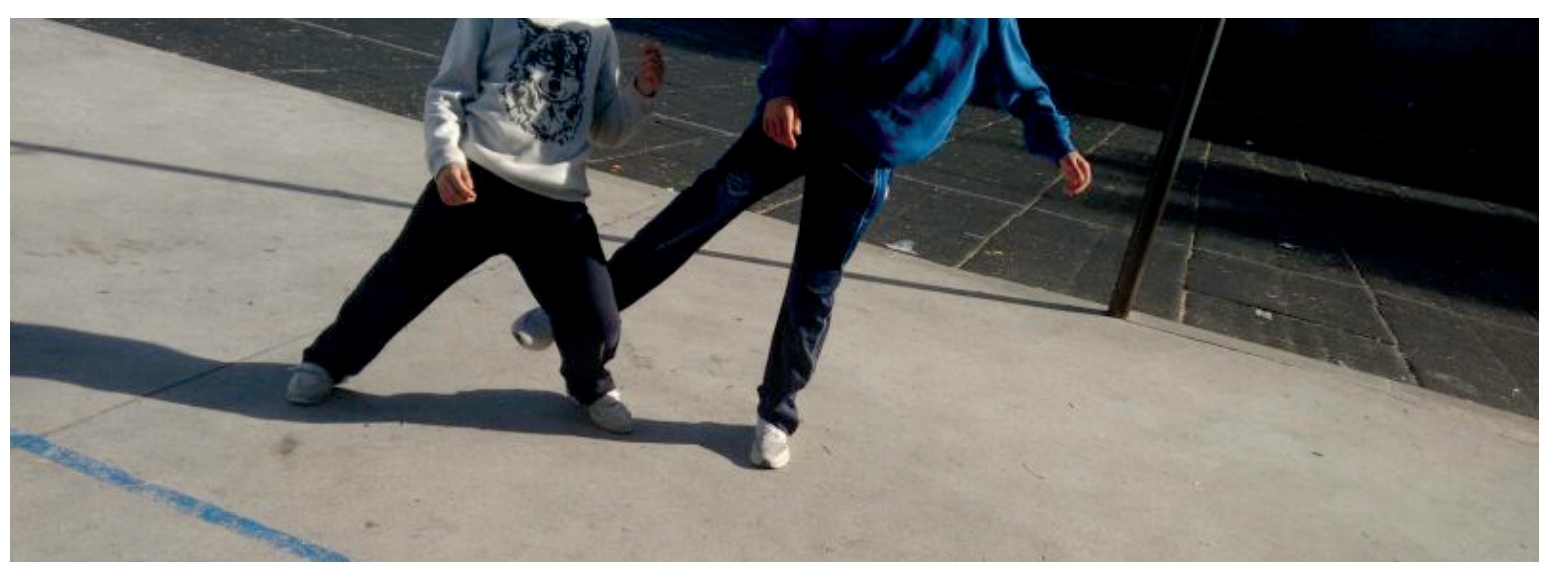

Las manifestaciones independientes proporcionadas por ambas maestras permiten intuir la existencia de un vínculo de carácter metafórico y metonímico entre sus imágenes experienciales y las fotografías que tomaron sobre la realidad del aula que vivieron en esos momentos. De alguna forma, aunque no tenían una gran alfabetización audiovisual, ni experiencia fotográfica, de forma intuitiva las dos han buscado la materialización de sus imágenes mentales sobre afectos y significados vividos, utilizando figuras retóricas y estilísticas, tal como la antítesis, la sinécdoque y la hipérbole visual.

\subsection{Resultados relacionados con las categorías emergentes}

Hasta este momento, en la codificación de los datos relacionados con las razones por las que ambas maestras hicieron cada una de las fotografías presentadas, han emergido dos grades tipos de categorías sobre las preocupaciones comunes que, a modo de fundamentos, llevaron a esta maestra a tomar esas imágenes:
5.2.1. - Preocupaciones relacionadas con alguna "dificultad en el desarrollo de la clase"

En varias de las sesiones mantenidas en el primer cuatrimestre de 2015, la profesora del colegio 1 manifestó su preocupación por el aburrimiento mostrado, provocado por muchas de las tareas que se realizaban en el aula. Por ejemplo, ante una de las fotografías donde tomó al alumnado con un plano medio, dijo:

"Maestra 1 (M1.): Esta fotografía la hice por la cara de aburrimiento que tenían muchos de estos niños, y eso que les pongo a trabajar por parejas"

Miembro grupo 1 (M.G.1): ¿Qué estaban haciendo?

M1: Los ejercicios de un tema de Lengua. Yo sé que muchas veces son rutinarios y poco atractivos, pero no queda más remedio que trabajarlos. Pero ese aburrimiento es algo que muchas veces le doy vueltas en la cabeza". (Fragmento de la sesión del 28/01/2015)

Esta preocupación de la maestra también se evocó en la sesión del 11 de febrero de ese año, al comentar la fotografía número 4 : 
Fotografía 4.

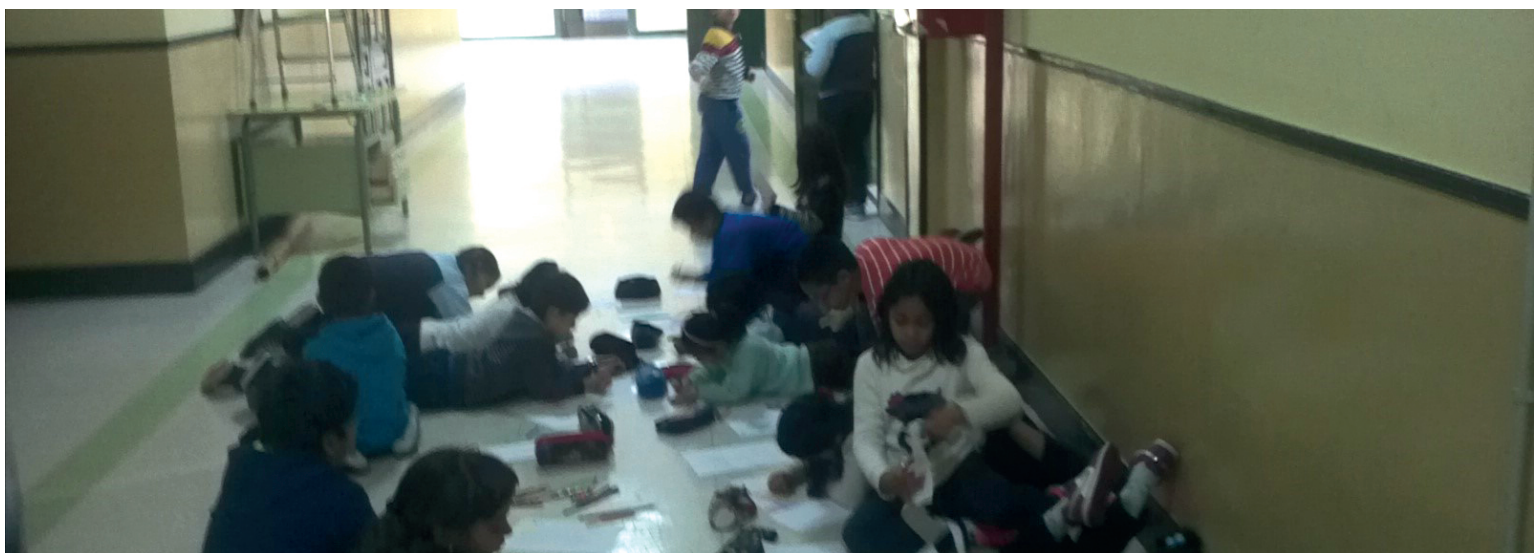

"M1: Esta fotografía corresponde al trabajo que estaban haciendo todos sobre el día de la Paz. Tenían que dibujar y escribir algo sobre la Paz, y luego teníamos que exponerlo en murales en el pasillo.

M.G.1: ¿Por qué están en el suelo en el pasillo, y no dentro del aula?

M1: Porque al ser el día de la Paz, tenía que decorar el pasillo junto a la compañera del aula de al lado. Como tenía que subir y bajar de la escalera, tenía que estar bastante tiempo fuera de clase. Yo no podía estar en los dos sitios, y ellos se iban revolucionando cada vez más, pues necesitan la referencia de un adulto.

M.G.1: ¿Y cómo se te ocurrió sacarlos al pasillo?
M1: Como no podía estar todo el tiempo en el aula, se me ocurrió que dibujasen en el pasillo, pensé que sería mejor porque los tendría controlados. Al estar yo allí los podía ver.

M.G.1: ¿Cómo valoras esa experiencia?

M1: La verdad es que me alegro, ellos se lo pasaron muy bien; se ve su cara. Funcionó mejor de lo que yo pensaba. Creo que cambiar el espacio de trabajo les vino muy bien". (Fragmento de la sesión del día 11/02/2015).

En la siguiente sesión, comprobamos que había cambiado la distribución de las mesas del aula. Antes estaban en tres filas de dos alumnos y ahora las mesas están haciendo una $\mathrm{U}$, según se observa en la fotografía 5 .

Fotografía 5.

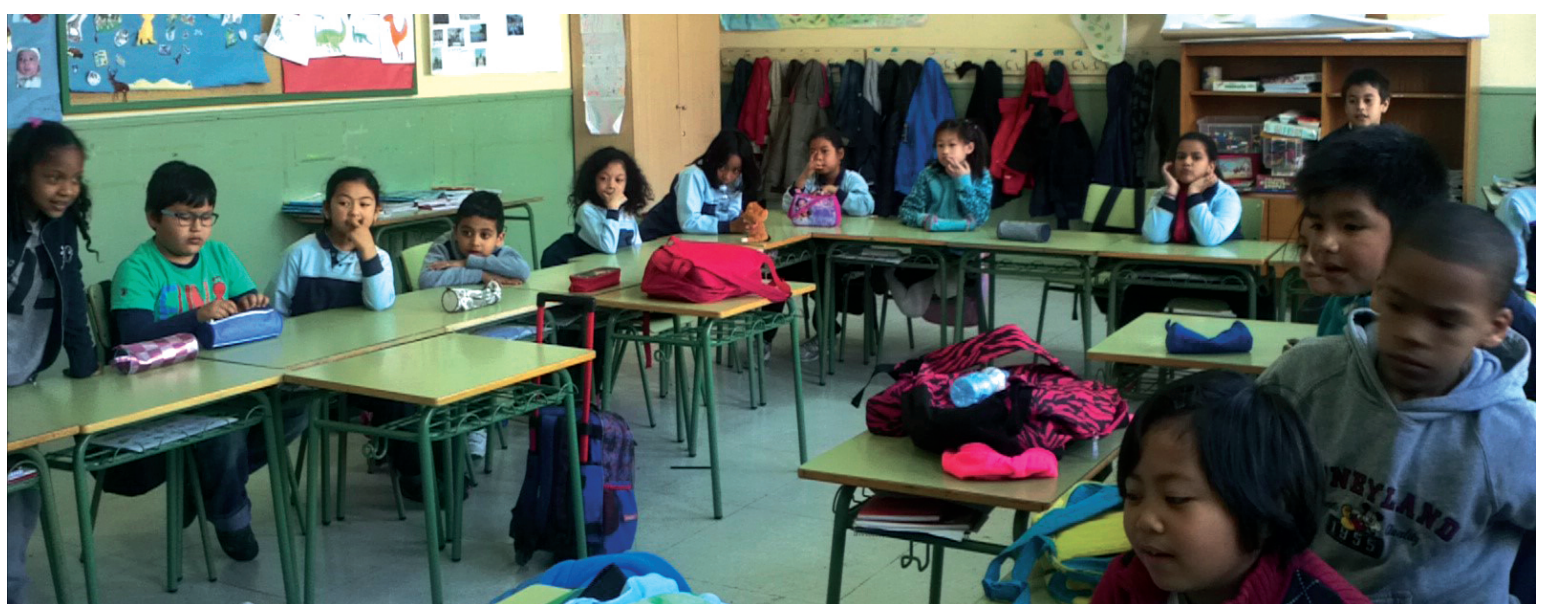


En dicha sesión de foto-elicitación, la maestra manifestó así las razones de este cambio de organización del espacio:

"M1: Después del éxito que tuvo la actividad de dibujar en el pasillo, apoyando las hojas y pinturas en el suelo, pensé que cambiar el contexto de las tareas era bueno para motivarlos a hacerlas bien. Y, por eso, entre las posibilidades de cambio que había en la clase, estaba la de colocar las sillas y mesas de otra forma.

M.G.1: ¿Por qué elegiste esa ubicación en U?

M1: Porque les permite poder verse las caras cuando hablamos sobre un tema. Además, claro, de poder hacer actividades individuales cuando es el momento.

M.G.1: Por ejemplo, sobre Matemáticas.

M1: Sí, claro."(Fragmento de la sesión del día 25/02/2015).

\subsection{2. - Motivaciones vinculadas a "problemas per- sonales del alumnado"}

Han sido frecuentes las fotografías que hicieron ambas maestras motivadas por el comportamiento especial realizado por algún alumno. Era "especial" porque, a diferencia del caso anterior que era una dificultad que mostraba buena parte de la clase, en este tipo de preocupación de la profesora sólo era un niño o niña quien manifestaba esa conducta y, como se verá, esta no pasaba desapercibida para el grupo. En este apartado de datos únicamente describiremos tres de estas situaciones difíciles. La primera está relacionada con el niño que llamaremos J. Ante la fotografía número 1 ya mostrada y comentada, la profesora expuso:

"M1: Esta fotografía la hice cuando J tuvo uno de los bloqueos que de vez en cuando le dan. Es un niño rico, que comparte todo y tiene buenas notas, pero cuando menos lo esperas tiene una forma bastante rara de llamar la atención. Por ejemplo, según se ve en la fotografía, había empezado a golpear el estuche contra la mesa. Yo no le hice caso, para ver si paraba; pero él fue a más hasta llegar a gritar. Fue en ese momento cuando hice la foto, para recordar cómo varios compañeros se levantaros para atenderle y cómo otros se tapaban los oídos para protegerse de los chillidos. M.G.1: ¿Y tú qué hiciste?

M1: Dejé pasar unos 10 segundos, confiando que el niño pararía; pero no, además de chillar empezó a golpearse la cabeza contra la mesa. El susto que me llevé hizo que rápidamente fuese para sujetarle y evitar que se autolesione.

M.G.1: ¿Cómo te sentiste?

M1. ¡Te lo puedes imaginar!. Con un sentimiento de impotencia de no saber bien qué hacer. Pensándolo ahora, fue un dilema; por una lado no quería intervenir para no reforzar esa forma de llamar la atención. Pero, por otra, se llegó a tal situación que tuve que hacerlo. El dilema fue ese ¿cuándo intervenir? episodios?

M.G.1: ¿Sabes por qué se inician esos

M1: La verdad es que no lo sé. Esto ya lo he hablado con la orientadora. Pensamos que es un niño muy sensible y, por algo que no sabemos bien si es porque alguien le ha hablado alto, o porque no se le hace caso, entonces se asusta, se bloquea e inicia esa forma autodestructiva de llamar la atención.

M.G.1: ¿Lo habéis comunicado a la familia?

M.1: Sí, la orientadora ya habló con la familia a raíz de los primeros episodios al principio del curso. Pero la familia dice que en su casa nunca ha tenido un comportamiento así. De todas formas, estoy de acuerdo con la orientadora cuando dice que esta anomalía es un comportamiento aprendido de llamar la atención y, por la edad que tiene, es fácil que provenga de su entorno familiar, aunque ellos lo nieguen”. (Fragmento de la sesión del día 11/02/2015).

El segundo caso que exponemos corresponde al niño que denominamos A. La maestra del colegio 1 lo expuso al mostrarnos la fotografía número 6 en una sesión. 


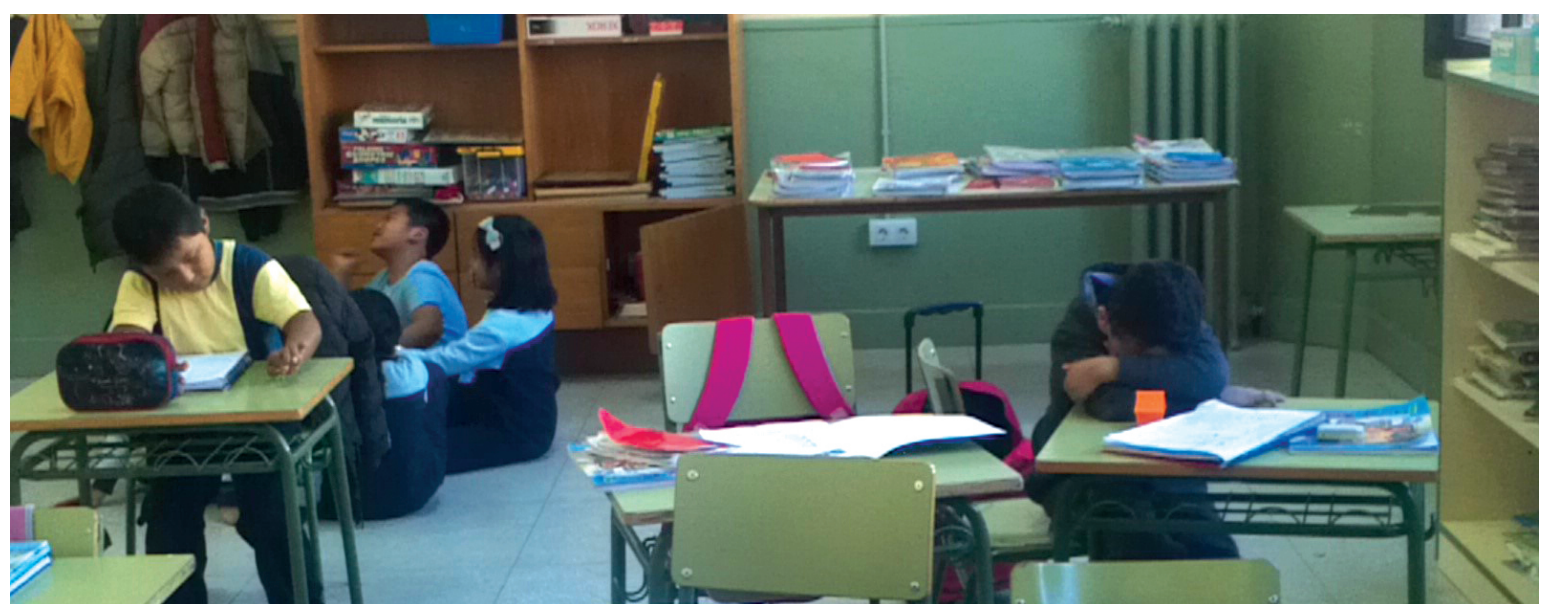

"M1: Hoy también quiero contaros un caso que me está preocupando, sobre todo por la relación que estoy teniendo con los padres. Es el de A, y se puede ver en esta fotografía (ver número la número 6) que he hecho y quiero comentaros. Es un niño que trabaja bien pero, a veces, cuando le llamas la atención o no le das lo que pide, toma actitud rara. Una vez se puso a correr por entre las mesas, y otra, se cruza de brazos y pone la cabeza sobre ellos como se ve en la foto. caso?

M.G.1: ¿Qué pasó, cómo actuaste en este

M1: No había hecho los deberes en casa y lo dejé sin recreo para que los hiciese en ese tiempo. En el recreo no los hizo, y se puso en la postura que muestra la fotografía (ver la número 6). Le dije varias veces que los hiciese, pero él siguió en esa actitud. Como dejé de decirle que los hiciese, pues entonces se levantó y se fue hacia una de las paredes de la clase, para llamar más la atención.

M.G.1: Pero eso hay que atajarlo, porque los otros niños lo aprenden.

M1: Sí, esta semana he hablado con los padres y me he quedado disgustada, sobre todo por su contradicción que no llevo bien.

M.G.1: ¿Qué contradicción?

M1: En el mes de diciembre me dijeron que no fuera tan dura con el niño porque lo dejaba sin recreo cuando no hacía algún trabajo, sabiendo que él puede hacerlo. Pero ahora, textualmente el padre me dijo que en la educación de su hijo su mujer hace de poli mala y él hace de poli bueno; y como yo soy mujer tengo que hacer de poli mala. Yo pensé que la madre no estaría de acuerdo con esto, pero no, me dijo que el niño se comporta así porque yo no le doy miedo, que tengo que actuar de otra forma, como ella hace, poniendo orden. Yo le dije que el miedo y el respeto no van unidos y que seguiría así. Ella me dijo que debería ser más dura. Por eso, no lo entiendo, antes me decían que no le castigase y ahora, que sigo actuando igual, me dicen que sea más dura con él. M.G.1: ¿Cómo te sientes?

M1: El disgusto me lo llevé a casa. Yo quiero ayudarles, pero los padres no entienden lo que hago, y que cada vez te digan una cosa no me ayuda". (Fragmento de la sesión del día 22/04/2015).

La tercera y última situación corresponde a la vivida y expuesta por la maestra del colegio 2:

"Maestra 2 (M2): La primera fotografía que os envié por whatsApp es donde están de espaldas K, A y N (alumnas) en situación de reflexión después de un conflicto de celos vividos en el aula después del recreo.

M.G.2: ¿Qué quieres decir con un conflicto de celos?

M2: Que K está saliendo con un compañero, y este "tontea" también con A. Hecho que 
molesta a $\mathrm{K}$, y se lo reprocha a $\mathrm{A}$. $\mathrm{N}$ es una amiga de clase que apoya a $\mathrm{A}$.

M.G.2: ¿Qué es lo que desencadenó que tomases esa fotografía?

M2: Al entrar al aula vi que había una fuerte discusión de voces y empujones de A y $\mathrm{N}$ hacia $\mathrm{K}$.

\section{M.G.2: ¿Cómo procediste?}

M2: Inmediatamente me interpuse entre ellas, y las llevé a esa zona del aula, les dije que se sentaran para que se relajasen. Las coloqué de tal forma para que no se mirasen entre sí, porque pienso que si siguen mirándose de frente la discusión continúa y progresa.

M.G.2: ¿Es así como procedes siempre ante casos como este?

M2: Sí, porque creo que para poder pensar y reflexionar sobre algo es necesario estar tranquilo emocionalmente, y esta forma de proceder llevó a las tres alumnas a ese relax. Sólo después, ya con calma, pudimos hablar de lo que había pasado". (Fragmento de la sesión del 20/04/2016).

Contemplando las respuestas de ambas maestras ante las preguntas formuladas por los miembros del grupo de discusión observamos que contienen las creencias, valores y teorías que tienen sobre la enseñanza pues muchas de ellas empiezan por "creo que..., o "pienso que..", etcétera.

\section{Conclusiones}

Sobre la relación entre las imágenes mentales que recogen las experiencias vividas por ambas profesoras en momentos determinados de su práctica docente y la representación que hacen de ellas mediante la fotografía, a la que hacía referencia el objetivo 1, se puede decir que, bien de forma deliberada o de manera intuitiva, estas dos maestras han utilizado distintas figuras retóricas de la imagen (metáfora e hipérbole visual, sobre todo), para representar y comunicar mediante una fotografía lo que tenían en su mente como consecuencia de los significados y emociones que estaban viviendo en esa situación de aula. Por ejemplo, tomar la imagen de un niño sentado en una silla, alejado de todo el grupo, mirando a la pared, evoca el significado y el sentimiento de soledad. Eso es lo que vivió la maestra del colegio 1 y, entre todas las fotografías posibles, lo expresó de forma concreta con esa imagen (fotografía 1).

Atendiendo al segundo objetivo, el cambio efectuado en la práctica de la maestra, contemplando los resultados obtenidos hasta finales del mes de junio de 2016, es pertinente afirmar que sí se está produciendo un cambio en su forma de diseñar y desarrollar las situaciones de enseñanza. Es así porque, según se ha expuesto en el apartado de resultados, entre otras transformaciones, las profesoras modificaron la distribución de las mesas del alumnado, así como el planteamiento de las tareas a realizar, buscando que éstas fueran más relevantes o próximas a sus vidas. También, podemos decir que las motivaciones comunes que han mostrado estas maestras para realizar ese cambio son de dos tipos: mejorar las tareas escolares en el aula y atender las dificultades personales de sus alumnos. En este sentido, respecto a las razones que llevaron a ambas profesoras a tomar fotos y en base al contenido y preocupaciones comunes expresadas por ellas, podemos manifestar que, principalmente, son las situaciones y conflictos personales y familiares del alumnado, como las agresiones físicas o los conflictos emocionales (situaciones de celos, marginación, etcétera).

A modo de reflexiones finales, hemos de indicar que la función básica de la fotografía en los procesos de discusión o foto-elicitación fue ralentizar los procesos de análisis de lo manifestado verbalmente por los participantes. Asimismo, estas pausas hicieron posible describir e interpretar el contenido relatado en el que se podían contemplar y comentar sus teorías, creencias y valores.

Entendemos que estos resultados ayudan a mejorar el uso de lenguajes audiovisuales en el desarrollo profesional del profesorado, así como los procesos de discusión generados en las sesiones de foto-elicitación, porque están contribuyen- 
do a que dos maestras, en nuestro caso, conozcan y fomenten más sus relaciones con el resto de los miembros de la comunidad educativa.

\section{Notas}

1. Proyecto subvencionado por el Ministerio de Economía y Competitividad del Gobierno de España, dentro del Plan Estatal $I+D+i$, referencia EDU2014-57103-R.

\section{Referencias bibliográficas}

Bach, H. (2007). Composing a Visual Narrative Inquiry. En D.J. Clandinin (Ed.), Handbook of Narrative Inquiry. Mapping a Methodology (pp. 280-307). London: Sage.

Barbour, R. (2013). Los grupos de discusión en Investigación Cualitativa. Madrid: Morata.

Bautista, A. (2014). La escuela como medio de relación entre familias inmigrantes y ciudad: datos de un caso. En A. Moclús \& C. Sabán (Coord.), Ciudad y educación: antecedentes $y$ nuevas perspectivas (pp. 99-116). Madrid: Síntesis.

Bruner, J. (2000). La escuela, puerta a la cultura. Madrid: Visor.

Clandinin, D.J., \& Connelly, F.M. (2000). Narrative Inquiry: Experience and Story in Qualitative Research. San Francisco, CA: Jossey-Bass.
Clark-Ibañez, M. (2007). Inter-City Children in Sharper Focus. Sociology of Childhood and Photo Elicitation Interviews. En Gr. C. Stanczak (Ed.), Visual Research Methods (pp. 167-196). Los Ángeles, CA: Sage.

Elliot, J. (1990). La investigación-acción en educación. Madrid: Morata.

Gibbs, G. (2012). El análisis de datos cualitativos en investigación cualitativa. Madrid: Morata.

Gimeno, J. (1988). El curriculum: una reflexión sobre la práctica. Madrid: Morata.

Harper, D. (2002). Talking about pictures: a case for photo elicitation. Visual Studies, 17(1), 13-26.

Kellner, D.M. (2004). Revolución tecnológica, alfabetismos múltiples y reestructuración de la educación. En I. Snyder (Ed.), Alfabetismos digitales (pp. 238-256). Archidona: Ediciones Aljibe.

Lemon, N. (2007). Take a photograph: teacher reflection through narrative. Reflective Practice, 8(2),177191. https://doi.org/10.1080/14623940701288982

McKermann, J. (2008). Investigación-acción y curriculum. Madrid: Morata.

Schön, D. (1989). La formación de profesionales reflexivos. Barcelona: Paidós-MEC.

Stake, R.E. (1989). Investigación con estudio de caso. Madrid: Morata.

Zeichner, K.M. (2010). La formación del profesorado y la lucha por la justicia social. Madrid: Morata. 